\title{
The association between cannabis use and suicidal behavior in patients with psychiatric disorders: an analysis of sex differences
}

Leen Naji ${ }^{1}$, Tea Rosic ${ }^{2}$, Brittany Dennis ${ }^{3}$, Meha Bhatt $^{4}$, Nitika Sanger ${ }^{5}$, Jackie Hudson ${ }^{2}$, Natalia Mouravska ${ }^{6}$, Lehana Thabane $e^{4,7,8}$ and Zainab Samaan ${ }^{2,4,9^{*}}$

\begin{abstract}
Background: Cannabis is the most commonly used illicit drug. In the general population, its use has been linked to a heightened propensity for suicidal behavior (SB). We hypothesize that this association varies in patients with psychiatric disorders. SB is known to vary by sex and therefore an investigation of cannabis' association with SB must consider sex differences. The purpose of this study is to investigate the association between cannabis use and suicide attempts in men and women with psychiatric disorders.

Methods: We merged data collected for two studies based in Ontario, Canada $(n=985)$. We employed a multivariable logistic regression to assess the association between cannabis use and suicide attempts in men and women with psychiatric disorders.

Results: We analyzed data from 465 men and 444 women. Amongst these, 112 men and 158 women had attempted suicide. The average age of our participants was 40 years (standard deviation (SD) 12.4). We found no significant association between suicide attempts and cannabis use in men (odds ratio $(\mathrm{OR})=1.34,95 \%$ confidence interval (Cl) 0.81 , $2.22, p=0.260)$ or women ( $\mathrm{OR}=0.97,95 \% \mathrm{Cl} 0.61,1.54, p=0.884)$. In a sensitivity analysis using a sample of patients with substance use disorder only, the heaviness of cannabis use was associated with small but significant association with SB in men $(\mathrm{OR}=1.03,95 \% \mathrm{Cl} 1.01,1.05, p=0.007)$.

Conclusion: Our findings indicate that there is no association between cannabis use and suicidal behavior in men or women with psychiatric disorders unlike what was reported for the general population, though the heaviness of cannabis use may have an effect in men. The impact of cannabis use in psychiatric disorders needs ongoing examination in light of its common use, impending legalization with expected increased access and the uncertainty about cannabis' effects on prognosis of psychiatric disorders. In addition, research should continue to investigate modifiable risk factors of SB in this population of which cannabis is not a significant factor based on this study.
\end{abstract}

Keywords: Cannabis, Suicide, Sex differences, Psychiatric disorder

\footnotetext{
* Correspondence: samaanz@mcmaster.ca

${ }^{2}$ Department of Psychiatry and Behavioral Neurosciences, McMaster

University, 100 West 5th Street, Mood Disorders Program, Hamilton, Ontario

L8N 3K7, Canada

${ }^{4}$ Department of Health Research Methods, Evidence, and Impact, McMaster

University, Hamilton, Canada

Full list of author information is available at the end of the article
}

(c) The Author(s). 2018 Open Access This article is distributed under the terms of the Creative Commons Attribution 4.0 International License (http://creativecommons.org/licenses/by/4.0/), which permits unrestricted use, distribution, and reproduction in any medium, provided you give appropriate credit to the original author(s) and the source, provide a link to the Creative Commons license, and indicate if changes were made. The Creative Commons Public Domain Dedication waiver (http://creativecommons.org/publicdomain/zero/1.0/) applies to the data made available in this article, unless otherwise stated. 


\section{Background}

Cannabis is the most commonly used illicit substance worldwide, and its consumption is only expected to increase as more jurisdictions, including Canada, legalize recreational use [1-4]. While this legislation may serve to lower societal costs associated with criminal penalties, the increased consumption of cannabis will likely lead to an increased prevalence of its various detrimental consequences on memory, judgment, cognition, and mental health [3-5].

Cannabis use has consistently been shown to be associated with a heightened propensity for suicidal behavior (SB) in the general population [6-9]. A twin study, for instance, revealed that amongst a sample of 277 same-sex twin pairs, cannabis users were 2.9 times more likely to attempt suicide than their non-cannabis-dependent co-twin.[6]. A prospective cohort study also found a robust association between regular cannabis use and suicide attempt after adjusting for important cofounders (odds ratio $(\mathrm{OR})=$ 2.9, 95\% confidence interval (CI) 1.3, 6.1) [9].

However, the majority of the studies investigating the aforementioned association included general population cohorts and limited characterization of psychopathology in the participants being studied. Given the high prevalence of cannabis use in patients with psychiatric disorders and the detrimental impact of suicide on individuals and societies, uncovering the associations, if any, between cannabis use and risk of suicide in this patient population is critical [10-12].

Furthermore, there is an abundance of evidence to suggest that women are more frequently diagnosed with psychiatric illnesses, in particular anxiety and depression, compared to men [13-15]. Women have also repeatedly been shown to have an increased risk of attempting suicide in the general population [16, 17]. Given this, we sought to determine the association between cannabis use and suicide attempt in women and men with psychiatric disorders separately. We hypothesize that cannabis use will be associated with an even greater risk of attempting suicide in women compared to men, given that women have been shown to be more susceptible to the detrimental mental, medical and social consequences of substance use including cannabis [15, 18-21]. For instance, compared to men, women have repeatedly been shown to become more rapidly addicted to drugs, suffer from more severe medical problems despite less heavy use (e.g., chronic obstructive pulmonary disease or alcoholic liver disease), and report more intense subjective responses to drug use [15, 22, 23]. A study by Patton et al. found that although the prevalence and heaviness of cannabis use is greater amongst men, women who used cannabis daily had more than a fivefold increase in the risk of having depression or anxiety compared to non-users, whereas no association was found in the same analysis of men [24].
This is the first study, to our knowledge, to investigate the association between cannabis use and suicidal behavior in the psychiatric population by sex. Our findings will assist in stratifying the risk of suicide attempt in psychiatric patients, who are amongst the most likely to attempt suicide [12, 19]. Provided the World Health Organization's (WHO) Mental Health Action Plan to reduce the rate of suicide by $10 \%$ by 2020 , as well as the legalization of cannabis in Canada to start September 2018, our study is both timely and relevant [18].

\section{Methods}

\section{Data collection}

We merged patient data that were obtained using similar protocols to collect homogenous data on adults with psychiatric disorders for two studies whose methods have previously been described [20, 25]. Briefly, these two studies are the Genetics of Opioid Addiction (GENOA) study, a prospective cohort study of opioid use disorder using structured scales to assign psychiatric diagnoses, and the Determinants of Suicidal Behavior: Conventional and Emergent Risk (DISCOVER) study, a case-control study of SB using the same diagnostic methods to reach a psychiatric diagnosis including substance use [20, 25]. These studies were approved by the Hamilton Integrated Research Ethics Board (10-661, 11-3479, and 11-056). In order to be included into the current study, participants had to be 18 years of age or older, provided written informed consent, must have been interviewed by trained research personnel using the Mini-International Neuropsychiatric Interview (M.I.N.I.) and must have also had at least one confirmed psychiatric diagnosis based on the M.I.N.I. The M.I.N.I. is a fully validated alternative to the Structured Clinical Interview for the Diagnostic and Statistical Manual of Mental Disorders' (DSM-IV) diagnoses and the Composite International Diagnostic Interview for the International Classification of Diseases, Tenth Revision (ICD-10) [26]. From both studies, 683 and 302 patients were screened for inclusion into our present study $(n=$ 985). See participants' flow diagram (Fig. 1).

Our primary outcome was the presence or absence of a lifetime suicide attempt based on patients' dichotomous response to the question "Did you ever make a suicide attempt?" on the M.I.N.I., coded "yes" or "no." Cannabis use was also a dichotomous covariate based on participants' response to the question on the M.I.N.I., "In the past 12 months, did you take any of [hashish, "hash", THC, "pot", "grass", "weed", or "reefer"] more than once, to get high, to feel elated, to get "a buzz" or to change your mood?". The past 12 months of cannabis use is commonly used in published literature to identify cannabis users $[9,27]$. Data on heaviness of cannabis use in the GENOA sample was also obtained through 


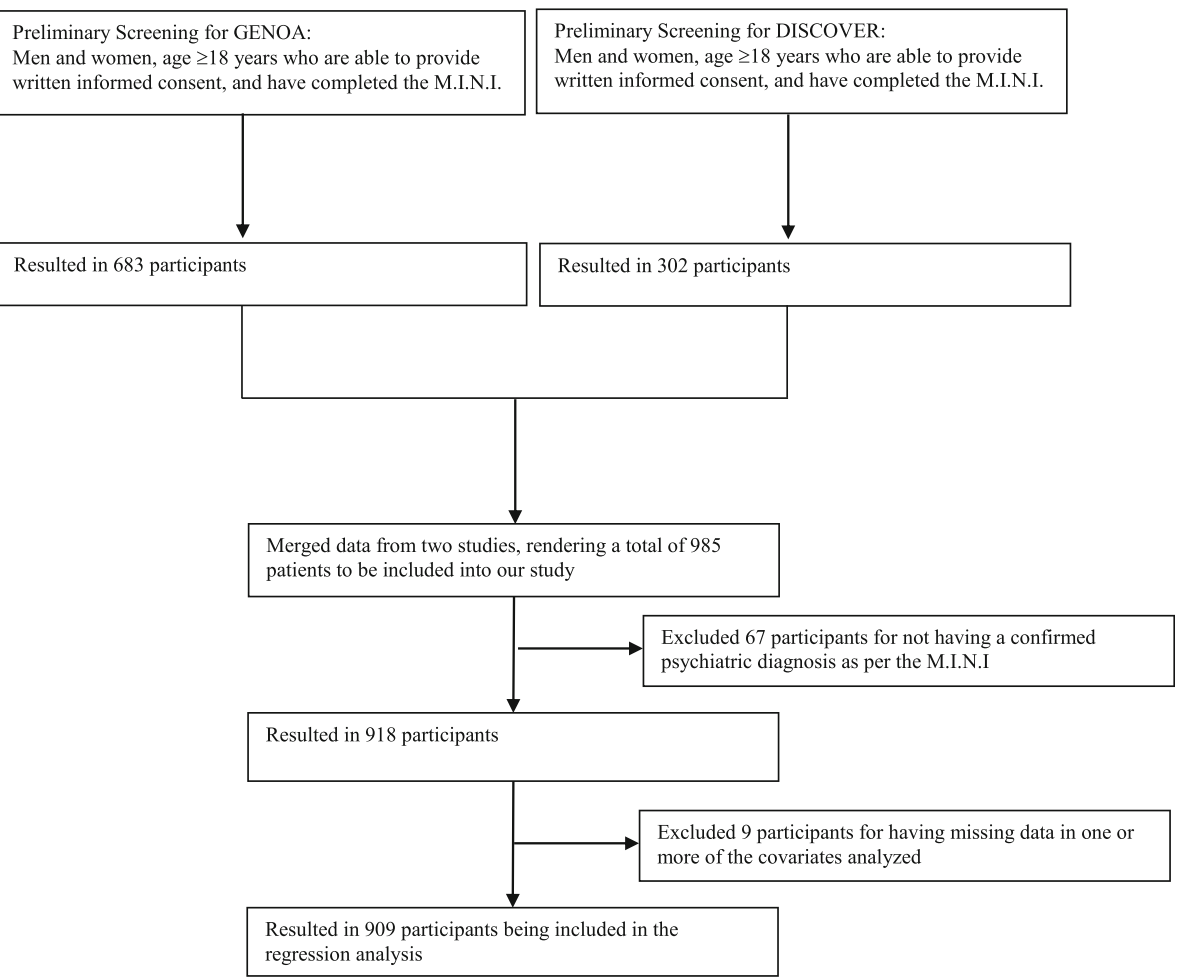

Fig. 1 Participant inclusion diagram

participants' reported "average number of days of cannabis use in the past 30 days" as part of the Maudsley Addiction Profile [28]. Demographic data including age, sex, marital and employment status were obtained through face-to-face interviews with all study participants as previously described [20, 25]. Psychiatric diagnoses were made if patients met the criteria on the M.I.N.I. for that specific diagnosis during their intake interview. Patients diagnosed with co-occurring psychiatric disorders were classified as having a single principal diagnosis as per the DSM-IV hierarchy of diagnoses [29].

\section{Statistical analysis}

We used descriptive statistics to summarize the participants' demographic and baseline characteristics. We reported continuous variables using mean (standard deviation (SD)) and categorical variables using proportions (percent).

A multi-variable logistic regression model with suicide attempt as the dependent variable and cannabis use as the explanatory variable was employed to determine the strength of the association between cannabis use and suicide attempts in the entire sample, while adjusting for the following clinically relevant factors: sex, age, marital status, employment status, and psychiatric diagnoses. Two additional multi-variable logistic regressions using the same independent and dependent variables described above were conducted for men and women separately.
Lastly, a separate analysis was conducted including the interaction variable "sex"cannabis use." The most commonly found primary psychiatric diagnoses were substance use disorders (including drugs other than cannabis), mood disorders (including depression and bipolar disorders), anxiety disorders (including generalized anxiety, social anxiety, obsessive-compulsive and post-traumatic stress disorders), and psychotic disorders (including schizophrenia, schizophreniform, schizoaffective, delusional, and brief psychotic disorder). However, the covariate "substance use disorder" (which included drugs other than cannabis) was eliminated from the analysis due to a high level of collinearity as per the variance inflation factor.

We conducted a sensitivity analysis using data from the GENOA sample to look at the impact, if any, of heaviness of cannabis use on suicide attempt in men and women with psychiatric diagnoses. Lastly, we conducted secondary analyses investigating the association between cannabis use (yes/no) and suicide attempts amongst GENOA and DISCOVER participants separately, to ensure robustness of our findings. Our study was adequately powered to detect an association using our logistic regression analyses with well more than 10 events per predictor variable [30]. Specifically, we analyzed data from 465 men and 444 women against 7 covariates (age, employment, marital status, cannabis use, mood, anxiety, and psychotic disorders). All statistical analyses were conducted using Stata 13 [31]. 


\section{Results}

\section{Participant characteristics}

Amongst the 985 participants included in our study, 76 participants were excluded for having missing data in one or more of the covariates analyzed (Fig. 1). Therefore, 909 participants were included in the regression analysis.

The mean age of participants included in our study was 40.2 years $(\mathrm{SD}=12.4)$. Amongst the 909 participants, more women $(n=158)$ than men $(n=112)$ reported attempting suicide $(\mathrm{OR}=1.48,95 \% \mathrm{CI} 1.09,2.01, p=$ $0.012)$. Men reported twice as much rate of cannabis use compared to women (45.6 versus $23.4 \%$, respectively). Please see Table 1 for a full description of the participants' characteristics.

\section{Suicide attempts and cannabis use}

No significant association was found between cannabis use and suicide attempts amongst the total sample of psychiatric patients $(\mathrm{OR}=1.08,95 \%$ CI $0.77,1.51, p=$ 0.663). However, our findings did reveal that amongst participants with psychiatric disorders, having a mood disorder $(\mathrm{OR}=2.83,95 \% \mathrm{CI} 1.90,4.23, p<0.001)$ or being a woman $(\mathrm{OR}=1.48,95 \% \mathrm{CI} 1.09,2.01, p=0.012)$ is associated with an increased risk of suicide attempt, while having a job is protective against suicide attempts $(\mathrm{OR}=0.34,95 \%$ CI $0.24,0.48, p<0.001)$. When the same statistical model described above is used to analyze

Table 1 Participant characteristics $(n=909)$

\begin{tabular}{|c|c|c|c|c|}
\hline \multirow{2}{*}{\multicolumn{2}{|c|}{ Participant characteristic }} & $\begin{array}{l}\text { Total } \\
(n=909)\end{array}$ & $\begin{array}{l}\text { Men } \\
(n=465)\end{array}$ & $\begin{array}{l}\text { Women } \\
(n=444)\end{array}$ \\
\hline & & & & \\
\hline \multirow{2}{*}{\multicolumn{2}{|c|}{ Current age (years) }} & $40.2(12.4)$ & $40.7(12.3)$ & 39.7 (12.5) \\
\hline & & $\begin{array}{l}N(\% \text { of } \\
\text { total) }\end{array}$ & $\begin{array}{l}N(\% \text { of } \\
\text { men) }\end{array}$ & $\begin{array}{l}N \text { (\% of } \\
\text { women) }\end{array}$ \\
\hline \multirow{2}{*}{$\begin{array}{l}\text { History of suicide } \\
\text { attempt }\end{array}$} & No & $639(70.3)$ & $353(75.9)$ & $286(64.4)$ \\
\hline & Yes & $270(29.7)$ & $112(24.1)$ & $158(35.6)$ \\
\hline \multirow[t]{2}{*}{ Employed } & No & $598(65.8)$ & $281(60.4)$ & $317(71.4)$ \\
\hline & Yes & $311(34.2)$ & $184(39.6)$ & $127(28.6)$ \\
\hline \multirow[t]{2}{*}{ Marital status } & $\begin{array}{l}\text { Married or living } \\
\text { with partner }\end{array}$ & $277(30.5)$ & $139(29.9)$ & $138(31.1)$ \\
\hline & Other & $632(69.5)$ & $326(70.1)$ & $306(68.9)$ \\
\hline \multirow[t]{2}{*}{ Cannabis use } & No & $571(62.8)$ & $253(54.4)$ & $318(71.6)$ \\
\hline & Yes & $338(37.2)$ & $212(45.6)$ & $126(23.4)$ \\
\hline \multirow{2}{*}{$\begin{array}{l}\text { Substance use } \\
\text { disorder }\end{array}$} & No & $172(18.9)$ & $64(13.8)$ & $108(23.3)$ \\
\hline & Yes & $737(81.1)$ & $401(86.2)$ & $336(75.7)$ \\
\hline \multirow{2}{*}{$\begin{array}{l}\text { Psychotic } \\
\text { disorder }\end{array}$} & No & $898(98.8)$ & $459(98.7)$ & $439(98.9)$ \\
\hline & Yes & $11(1.21)$ & $6(1.29)$ & $5(1.13)$ \\
\hline \multirow[t]{2}{*}{ Mood disorder } & No & $758(83.4)$ & $409(88.0)$ & $349(78.6)$ \\
\hline & Yes & $151(16.6)$ & $56(12.0)$ & $95(21.4)$ \\
\hline \multirow[t]{2}{*}{ Anxiety disorder } & No & $899(98.9)$ & $463(99.6)$ & $436(98.2)$ \\
\hline & Yes & $10(1.10)$ & $2(0.43)$ & $8(1.80)$ \\
\hline
\end{tabular}

GENOA and DISCOVER data separately, the association between cannabis use and suicide attempt remained insignificant (data not shown). Lastly, the interaction term "sex*cannabis use" remained insignificant when included in the logistic regression model (data not shown).

\section{Sex differences}

Cannabis use was not found to be significantly associated with suicide attempts in women $(\mathrm{OR}=0.97,95 \% \mathrm{CI}$ $0.61,1.54, p=0.884)$ or men $(\mathrm{OR}=1.34,95 \%$ CI 0.81 , 2.22, $p=0.260)$. Please see Table 2 .

\section{Sensitivity analysis: heaviness of cannabis use}

Within the GENOA sample, heaviness of cannabis use was found to be significantly associated with suicide attempt in men $(\mathrm{OR}=1.03,95 \% \mathrm{CI} 1.01,1.05, p=0.007)$, but not women (OR $=0.99,95 \%$ CI 0.97, 1.01, $p=0.277)$. See Table 3 in Appendix.

\section{Discussion}

Findings from this study suggest that amongst patients with a psychiatric comorbidity, women, unemployed individuals, and those with mood disorders are at a significantly heightened risk of attempting suicide. Heaviness of cannabis use was also found to be associated with an increased risk of suicide attempt in men in a subset of the study sample. Contrastingly, no association was found between the risk of attempting suicide and cannabis use, marital status, age, or having an anxiety or psychotic disorder. Interestingly, the negative impact of a mood disorder and the protective effect of employment were more pronounced in men compared to women with psychiatric disorders.

While cannabis use in the general population leads to an increased risk of suicide attempts as seen in some studies, our findings suggest that this association does not hold true in a large cohort of psychiatric patients who are at an already heightened risk of attempting suicide [6-9]. Heaviness of cannabis use was, however, found to have a slight but significant association with suicide attempt in men in a subset of our study sample. The pathophysiological link between cannabis use and suicidal behavior in the general population has yet to be established, though both direct and indirect associations between cannabis use and suicide attempt have been hypothesized [9]. One hypothesis suggests that tetrahydrocannabinol (THC, the active ingredient of cannabis) has direct neurophysiological effects that lead to impaired cognition and behavior, whereas another hypothesis suggests that cannabis use indirectly increases one's risk for suicide attempt because cannabis users tend to have other predisposing social factors that increase their risk of attempting suicide [9]. Having a psychiatric disorder including other substance use is likely associated with 
Table 2 Association between cannabis use (yes/no) and suicide attempt in psychiatric patients

\begin{tabular}{|c|c|c|c|c|}
\hline \multirow[b]{2}{*}{ Covariates } & \multicolumn{2}{|l|}{ Women $(n=444)$} & \multicolumn{2}{|l|}{ Men $(n=465)$} \\
\hline & Odds ratio $(95 \% \mathrm{Cl})$ & $p$ value & Odds ratio $(95 \% \mathrm{Cl})$ & $p$ value \\
\hline Marital status & $1.03(0.67,1.61)$ & 0.880 & $0.62(0.36,1.07)$ & 0.084 \\
\hline Employed & $0.41(0.25,0.67)$ & $<0.001$ & $0.26(0.15,0.44)$ & $<0.001$ \\
\hline Age & $0.99(0.98,1.01)$ & 0.406 & $1.00(0.99,1.02)$ & 0.646 \\
\hline Cannabis use & $0.97(0.61,1.54)$ & 0.884 & $1.34(0.81,2.22)$ & 0.260 \\
\hline Psychotic disorder & $3.34(0.52,21.4)$ & 0.204 & $3.50(0.65,18.9)$ & 0.146 \\
\hline Anxiety disorder & $1.41(0.32,6.25)$ & 0.651 & - & - \\
\hline Mood disorder & $2.22(1.33,3.71)$ & 0.002 & $4.57(2.36,8.87)$ & $<0.001$ \\
\hline
\end{tabular}

altered neurophysiological state and therefore the effect of cannabis is less well known and difficult to isolate from the underlying psychopathology [32, 33].

It is also likely that the association between cannabis use and suicide risk described in the literature varies by the type of suicidal behavior. We have previously shown that certain epidemiological observations of suicide risk factors, such as obesity, differ for suicide ideation, attempts, and completed suicide [34]. In addition, we have also found that genetic risk factors associated with suicide also varied by the type of suicidal behavior [35]. Taken together, these observations call for homogenous definitions of suicidal behaviors in order to infer conclusions with any certainty on the association between certain risk factors and suicide.

Our significant findings related to suicide attempts and risk factors are mostly supported by existing literature. Previous studies have established that while men are at an increased risk of completing suicide, the prevalence of attempted suicide is significantly higher in women amongst the general population [16, 17]. Amongst psychiatric disorders, mood disorders are the most strongly associated with suicidal attempts [36]. Similarly, unemployment has been linked to a heightened risk of suicide. Whether this association is directly causal or indirectly associated with suicide by precipitating other risk factors for suicide, such as depression, has yet to be established [17, 37, 38]. Interestingly, the association between having a mood disorder and attempting suicide was twice as prominent in men as it was in women. Similarly, employment was more protective against suicide attempt in men compared to women. While such differences have not been previously reported, a plausible explanation may be the fact that women are already at a heightened risk of attempting suicide such that these additional predisposing factors may play a smaller role. A similar rationale may explain the significant association between heaviness of cannabis use and suicide attempt in men but not in women. This finding has not previously been reported in this population, and previous literature has actually revealed that even amongst cannabis users, women are more likely than men to attempt suicide [9]. It is possible that, given that women experience deleterious effects of cannabis use at lower doses and more frequently than men as we describe above, the dose response relationship is less pronounced [22, 24]. Ultimately, our study adds to the existing body of literature showing that the elevated suicidal behavior risk amongst women, the unemployed, and those with a mood disorder seen in the general population remains consistent in a cohort of psychiatric patients and that the effects of unemployment, mood disorders, and heavy cannabis use are more pronounced in men compared to women.

Our current study findings advance knowledge regarding suicide risk in psychiatric patients and warrant further investigation into the effect of cannabis on specific psychiatric disorders. With the WHO's plans to reduce suicide rate by $10 \%$ by 2020 , it is imperative that we establish clear risk factors to assist in stratifying individuals' suicidal risk [18]. While such data exist on a general population level, they are lacking amongst psychiatric patients who comprise a large proportion of patients with suicidal behavior. The prevalence of suicide attempt in our patient sample (29.7\%) falls on the higher end of the spectrum of what has previously been reported for psychiatric patients [39]. Given that $50 \%$ of patients who attempt suicide are known to have a concurrent substance use disorder, this finding is expected as the majority of patients in our sample have a substance use disorder [40].

Our study reveals that in a large population of psychiatric patients, women, those who are unemployed, those who have a mood disorder, and men with heavier cannabis use are at a heightened risk of attempting suicide and may therefore require closer follow-up, additional counseling, and/or screening for underlying mental health processes to mitigate the risk of SB [41]. Contrastingly, cannabis use as a whole does not seem to add to the suicide risk in this patient population despite its 
established association with suicide risk in the general population, though this effect may vary in certain subgroups and based on the amounts used. Nonetheless, cannabis use has been associated with other psychopathology such as mood and psychotic symptoms which may in turn increase the risk of suicide and therefore cannabis use in this high-risk population should not be overlooked [42].

\section{Limitations}

It is important to acknowledge the limitations of our findings. Firstly, we merged data from two studies that recruited patients for different purposes. However, the outcomes and covariates we analyzed in the present study were collected from all patients using the same consistent case report forms and the M.I.N.I., meaning that it should not have had an impact on our findings. Additionally, all patients included met the inclusion criteria of our present study, including the presence of a psychiatric diagnosis. It is also worth reiterating that our findings remained unchanged when data from both studies were analyzed separately, indicating robustness of our findings. However, when data on heaviness of cannabis use were investigated, which were available from one study only (GENOA), we noticed a significant association between heaviness of cannabis use and SB in men. This may indicate that the amount and/or frequency of cannabis use may have negative effects on SB and that further studies should examine the amount and frequency of cannabis use in psychiatric patients if we are to draw any firm conclusions.

Secondly, cannabis use and suicide attempt were based on self-report, inevitably subjecting our findings to social desirability bias. However, we can argue that the self-reported use of cannabis is relatively accurate despite the expected bias. In a previous study, we have shown self-reported cannabis use to be significantly associated with urine drug screen for cannabis with $79.9 \%$ sensitivity and $80.0 \%$ specificity [43]. Our primary question assessing cannabis use also specifies recreational use, which may exclude participants who believe their illicitly obtained cannabis is for medical use or those who obtain medicinal cannabis but use it recreationally, thus potentially biasing our findings towards the null. Once again, this is unlikely to have a major impact on the findings given that approximately $90 \%$ of adult cannabis users report recreational use [44].

Moreover, while it is important to identify suicide attempts in a longitudinal study, this is challenging due to the low incidence of suicide attempts and the need for a very large cohort that must be followed for a lengthy period of time making the study not feasible and the cost prohibitive. As such, the majority of the literature on cannabis use and suicide attempt relies on self-report in cross-sectional studies [6, 9]. It is also worth noting that we wanted to identify if differences exist based on how we captured the suicide question and thus conducted a secondary analysis using data from the 231 participants for whom we had access to hospital records of clinically documented suicide attempt, and we found that the association between cannabis use and suicide attempt (as per hospital records) remained insignificant (data not shown).

Lastly, given that our sample comprised of a large number of patients with opioid use disorder, it is possible that the established association between opioid use and SB as well as unintentional overdoses may have confounded our findings [45-47]. However, it is unlikely to have changed our results given that our results remained unchanged in a subgroup analysis of DISCOVER patients of whom a minority were patients with substance use disorders. Nonetheless, it may be worthwhile for future studies investigating the association between cannabis use and suicide attempt in psychiatric patients to stratify findings based on specific psychiatric comorbidities.

\section{Conclusion}

While previous research has demonstrated a positive association between cannabis use and suicide attempt in the general population [6-8], our study reveals that such association does not exist amongst both men and women with psychiatric disorders. However, the heaviness of cannabis use in men had a modest but significant association with suicide attempts in a subset of this study. The impact of cannabis use, although common, in people with psychiatric disorders is therefore different than that in the general population. This study identified significant risk factors for suicide attempts in psychiatric patients including being a women, being unemployed, and having a mood disorder, in keeping with previous research [16, 37, 38]. Findings from this study may serve to educate health professionals when stratifying patients' risk of suicide as well as policy makers when reviewing current strategies to mitigate suicide risk. This may include more aggressive treatment of mood disorders in primary care, more social services to support patients with psychiatric disorders to assist in job placements, skills development, and programs to encourage return to work plans. Further data on cannabis use including heaviness are also needed to identify those at risk of suicide attempts. Taken together, our findings provide data upon which we may base decisions when striving towards achieving the WHO's Mental Health Action Plan to reduce the rate of suicide by $10 \%$ by 2020 , by addressing modifiable risk factors such as unemployment as described above [18]. 


\section{Appendix}

Table 3 Association between heaviness of cannabis use and suicide attempt in psychiatric patients

\begin{tabular}{lllll}
\hline \multirow{2}{*}{ Covariates } & \multicolumn{2}{l}{ Women $(n=314)$} & & Men $(n=364)$ \\
\cline { 2 - 4 } Marital status & Odds ratio $(95 \% \mathrm{Cl})$ & $p$ value & $0.65(0.32,1.31)$ & 0.974 \\
Employed & $1.01(0.57,1.79)$ & 0.002 & $0.24(0.11,0.50)$ & $<$ value \\
Age & $0.33(0.17,0.66)$ & 0.185 & $1.01(0.98,1.04)$ & 0.226 \\
Cannabis days used & $0.98(0.96,1.01)$ & 0.277 & $1.03(1.01,1.05)$ & 0.001 \\
Psychotic disorder & $0.99(0.97,1.01)$ & 0.120 & $1.44(0.27,7.65)$ & 0.007 \\
Anxiety disorder & $2.91(0.76,11.1)$ & 0.068 & $3.27(1.42,7.57)$ & 0.006 \\
Mood disorder & $2.21(0.94,5.20)$ & $<0.001$ & $3.46(1.75,6.85)$ & $<0.000$ \\
\hline
\end{tabular}

This table contains the results of the sensitivity analysis investigating the association between the heaviness of cannabis use and suicide attempts amongst a sample of patients with substance use disorders. Heaviness of cannabis use was found to have a modest but significant association with suicide attempt in men $(\mathrm{OR}=1.03,95 \% \mathrm{Cl} 1.01,1.05, p=0.007)$, but not women $(\mathrm{OR}=0.99,95 \% \mathrm{Cl} 0.97,1.01, p=0.277)$

\section{Abbreviations}

Cl: Confidence interval; DISCOVER: Determinants of Suicidal Behavior: Conventional and Emergent Risk; DSM-IV: Diagnostic and Statistical Manual of Mental Disorders, Fourth Edition; GENOA: Genetics of Opioid Addiction; ICD-10: International Classification of Diseases, Tenth Revision; M.I.N.I.: MiniInternational Neuropsychiatric Interview; OR: Odds ratio; SB: Suicidal behavior; SD: Standard deviation; THC: Tetrahydrocannabinol; WHO: World Health Organization

\section{Acknowledgements}

We would like to thank the study participants for their generous contributions to the study.

\section{Funding}

The study is supported by grants from the Canadian Institutes for Health Research (CIHR), the Brain and Behaviour Research Foundation, and Hamilton Academic Health Sciences Organization (HAHSO).

\section{Availability of data and materials}

The dataset analyzed in the present study is available from the corresponding author upon reasonable request.

\section{Authors' contributions}

$L N, T S, B D, L T$, and $Z S$ are responsible for conceived and designed the experiments: $L N, T S, B D, M B, N S, J H, N M, L T$, and ZS were involved in acquisition of the data. $L N$, $\mathrm{TS}, \mathrm{BD}, \mathrm{MB}, \mathrm{NS}, \mathrm{LT}$, and $Z \mathrm{~S}$ analyzed the data. $\mathrm{LN}, \mathrm{TS}, \mathrm{BD}$, and ZS wrote the first draft of the manuscript. $L N, T S, B D, M B, N S, J H, N M, L T$, and ZS contributed to the writing of the final manuscript, made critical revisions and approved the final results and conclusions. All authors reviewed and approved of the final manuscript.

\section{Ethics approval and consent to participate}

These studies were approved by the Hamilton Integrated Research Ethics Board (10-661, 11-3479 and 11-056). All participants provided informed written consent to participate in our study.

\section{Competing interests}

The authors declare that they have no competing interests.

\section{Publisher's Note}

Springer Nature remains neutral with regard to jurisdictional claims in published maps and institutional affiliations.

\section{Author details}

${ }^{1}$ Department of Family Medicine, McMaster University, Hamilton, Canada. ${ }^{2}$ Department of Psychiatry and Behavioral Neurosciences, McMaster University, 100 West 5th Street, Mood Disorders Program, Hamilton, Ontario L8N 3K7, Canada. ${ }^{3}$ St. George's University of London, London, UK.
${ }^{4}$ Department of Health Research Methods, Evidence, and Impact, McMaster University, Hamilton, Canada. ${ }^{5}$ Medical Science Graduate Program, McMaster University, Hamilton, Canada. ${ }^{6}$ Hamilton Health Sciences, Hamilton, Ontario, Canada. 'Departments of Pediatrics and Anesthesia, McMaster University, Hamilton, Canada. 'Biostatistics Unit, Father Sean O'Sullivan Research Centre, St Joseph's Healthcare, Hamilton, Canada. ${ }^{9}$ Population Genomic Program, Chanchalani Research Centre, McMaster University, Hamilton, Canada.

Received: 9 March 2018 Accepted: 27 May 2018

Published online: 11 June 2018

\section{References}

1. United Nations Office on Drugs and Crime (UNODC), World Drug Report: Recent Statistics and Trend Analysis of Illicit Drug markets. 2012. Available at: http://www.unodc.org/documents/data-and-analysis/WDR2012/WDR_ 2012_Chapter1.pdf. Accessed 9 Jul 2017.

2. Task Force on Marijuana Legalization and Regulation. Toward the legalization. In: Regulation and restriction of access to marijuana: discussion paper; 2016.

3. Rocky Mountain High Intensity Drug Trafficking Area. The legalization of marijuana in Colorado: the impact. (Rocky Mountain High Intensity Drug Trafficking Area Volume 2). 2014

4. Hall W, Lynskey M. Evaluating the public health impacts of legalizing recreational cannabis use in the United States. Addiction. 2016:111:1764-73.

5. Volkow N, Baler R, Compton W, Weiss S. Adverse health effects of marijuana use. N Engl J Med. 2014:370(23):2219-27.

6. Lynskey MT, Glowinski AL, Todorov AA, et al. Major depressive disorder, suicidal ideation, and suicide attempt in twins discordant for cannabis dependence and early-onset cannabis use. Arch Gen Psychiatry. 2004;61(10): 1026-32.

7. Delforterie MJ, Lynskey MT, Huizink AC, et al. The relationship between cannabis involvement and suicidal thoughts and behaviors. Drug Alcohol Depend. 2015;150:98-104

8. Fergusson DM, Woodward LJ, Horwood LJ. Risk factors and life processes associated with the onset of suicidal behavior during adolescence and early adulthood. Psychol Med. 2000;30(1):23-39.

9. Pedersen W. Does cannabis use lead to depression and suicidal behaviours? A population-based longitudinal study. Acta Psychiatr Scand. 2008;118(5): 395-403.

10. Adlaf E, Paglia-Boak A. Drug use among Ontario students 1977-2007. Detailed findings from the Ontario Student Drug Use and Health Survey (Centre for Addiction and Mental Health Research Document Series No. 20). 2007

11. Adlaf E, Begin P, Sawka E. Canadian addiction survey (CAS): a national survey of Canadians' use of alcohol and other drugs: prevalence of use and related harms - a detailed report. Ottawa: ON: Canadian Centre on Substance Abuse; 2005. 
12. Chesney E, Goodwin GM, Fazel S. Risks of all-cause and suicide mortality in mental disorders: a meta-review. World psychiatry : official journal of the World Psychiatric Association (WPA). 2014;13(2):153-60.

13. Grant BF, Weissman MM. Gender and the prevalence of psychiatric disorders. In: Narrow WE, First MB, Sirovatk M, Regier DA, editors. Age and gender considerations in psychiatric diagnosis: a research agenda for DSMV. Arlington: American Psychiatric Association; 2007. p. 31-45.

14. World Health Organization. Gender and women's mental health. 2016 Available at: http://www.who.int/mental_health/prevention/genderwomen/ en/. Accessed 21 Dec 2016.

15. Hernandez-Avila CA, Rounsaville BJ, Kranzler HR. Opioid-, cannabis- and alcohol-dependent women show more rapid progression to substance abuse treatment. Drug Alcohol Depend. 2004;74(3):265-72.

16. Vijayakumar L. Suicide in women. Indian J Psychiatry. 2015;57(Suppl 2):S233-8.

17. Substance Abuse and Mental Health Services Administration. Results from the 2013 National Survey on Drug Use and Health: Mental Health Findings, NSDUH Series H-49, HHS Publication No. (SMA) 14-4887. Rockville, MD: Substance Abuse and Mental Health Services; 2014. Available at https://http://www.samhsa.gov/ data/sites/default/files/NSDUHmhfr2013/NSDUHmhfr2013.pdf

18. Mental Health Action Plan. 2013-2020. Geneva: World Health Organization; 2013.

19. Nock MK, Kessler RC. Prevalence of and risk factors for suicide attempts versus suicide gestures: analysis of the National Comorbidity Survey. J Abnorm Psychol. 2006;115(3):616-23.

20. Samaan Z, Bawor M, Dennis BB, et al. Exploring the Determinants of Suicida Behavior: Conventional and Emergent Risk (DISCOVER): a feasibility study. Pilot and feasibility studies. 2015;1:17.

21. Arfken CL, Klein C, di Menza S, Schuster CR. Gender differences in problem severity at assessment and treatment retention. J Subst Abus Treat. 2001; 20(1):53-7.

22. Haas AL, Peters RH. Development of substance abuse problems among drug-involved offenders. Evidence for the telescoping effect. J Subst Abus. 2000;12(3):241-53.

23. Sofuoglu M, Dudish-Poulsen S, Nelson D, Pentel PR, Hatsukami DK. Sex and menstrual cycle differences in the subjective effects from smoked cocaine in humans. Exp Clin Psychopharmacol. 1999;7(3):274-83.

24. Patton GC, Coffey C, Carlin JB, Degenhardt L, Lynskey M, Hall W. Cannabis use and mental health in young people: cohort study. BMJ (Clinical research ed. 2002;325(7374):1195-8.

25. Samaan Z, Bawor M, Dennis BB, et al. Genetic influence on methadone treatment outcomes in patients undergoing methadone maintenance treatment for opioid addiction: a pilot study. Neuropsychiatr Dis Treat. 2014;10:1503-8.

26. Sheehan DV, Lecrubier $Y$, Sheehan KH, et al. The Mini-International Neuropsychiatric Interview (M.I.N.I.): the development and validation of a structured diagnostic psychiatric interview for DSM-IV and ICD-10. The Journal of clinical psychiatry. 1998;59(Suppl 20):22-33. quiz 34-57

27. Patton GC, Coffey C, Carlin JB, Degenhardt L, Lynskey M, Hall W. Cannabis use and mental health in young people: cohort study. BMJ. 2002;325(7374): 1195-8.

28. Marsden J, Gossop M, Stewart D, Best D, Farrell M, Lehmann P, Edwards C, Strang J. The Maudsley addiction profile (MAP): a brief instrument for assessing treatment outcome. Addiction. 1998;93(12):1857-67.

29. American Psychiatric Association. (2000). Diagnostic and statistical manual of mental disorders: DSM-IV-TR. Washington DAPA

30. Peduzzi P, Concato J, Kemper E, Holford TR, Feinstein AR. A simulation study of the number of events per variable in logistic regression analysis. J Clin Epidemiol. 1996;49(12):1373-9.

31. StataCorp. Stata statistical software: release 13. In: College Station TSL; 2013.

32. Cheung CHM, McLoughlin G, Brandeis D, Banaschewski T, Asherson P, Kuntsi J. Neurophysiological correlates of attentional fluctuation in attention-deficit/hyperactivity disorder. Brain Topogr. 2017;30(3):320-32.

33. Dolsen MR, Cheng P, Arnedt JT, et al. Neurophysiological correlates of suicidal ideation in major depressive disorder: hyperarousal during sleep. J Affect Disord. 2017;212:160-6.

34. Perera S, Eisen RB, Dennis BB, et al. Body mass index is an important predictor for suicide: results from a systematic review and meta-analysis. Suicide \& life-threatening behavior. 2016;46(6):697-736.

35. Clayden RC, Zaruk A, Meyre D, Thabane L, Samaan Z. The association of attempted suicide with genetic variants in the SLC6A4 and TPH genes depends on the definition of suicidal behavior: a systematic review and meta-analysis. Transl Psychiatry. 2012;2:e166.
36. Kessler RC, Borges G, Walters EE. Prevalence of and risk factors for lifetime suicide attempts in the National Comorbidity Survey. Arch Gen Psychiatry. 1999;56(7):617-26.

37. Blakely TA, Collings SC, Atkinson J. Unemployment and suicide. Evidence for a causal association? J Epidemiol Community Health. 2003;57(8):594-600.

38. Kposowa AJ. Unemployment and suicide: a cohort analysis of social factors predicting suicide in the US National Longitudinal Mortality Study. Psychol Med. 2001;31(1):127-38.

39. Shibre T, Hanlon C, Medhin G, et al. Suicide and suicide attempts in people with severe mental disorders in Butajira, Ethiopia: 10 year follow-up of a population-based cohort. BMC psychiatry. 2014;14:150.

40. Canadian Centre on Substance Abuse. Substance use and suicide among youth: prevention and intervention strategies. Ottawa: ON: Canadian Centre on substance abuse; 2016.

41. Carrigan CG, Lynch DJ. Managing suicide attempts: guidelines for the primary care physician. Primary care companion to the Journal of clinical psychiatry. 2003;5(4):169-74.

42. Volkow ND, Baler RD, Compton WM, Weiss SRB. Adverse health effects of marijuana use. N Engl J Med. 2014;370:2219-27.

43. Zielinski L, Bhatt M, Sanger N, et al. Association between cannabis use and methadone maintenance treatment outcomes: an investigation into sex differences. Biol Sex Differ. 2017:8:8.

44. Schauer GL, King BA, Bunnell RE, Promoff G, Toking MATA. Vaping, and eating for health or fun: marijuana use patterns in adults, U.S., 2014 American journal of preventive medicine. 2016;50(1):1-8.

45. Gray D, Coon H, McGlade E, et al. Comparative analysis of suicide, accidental, and undetermined cause of death classification. Suicide \& lifethreatening behavior. 2014;44(3):304-16.

46. Wilcox HC, Conner KR, Caine ED. Association of alcohol and drug use disorders and completed suicide: an empirical review of cohort studies. Drug Alcohol Depend. 2004;(76 Suppl):S11-9.

47. Ashrafioun L, Bishop TM, Conner KR, Pigeon WR. Frequency of prescription opioid misuse and suicidal ideation, planning, and attempts. J Psychiatr Res. 2017;92:1-7

\section{Ready to submit your research? Choose BMC and benefit from:}

- fast, convenient online submission

- thorough peer review by experienced researchers in your field

- rapid publication on acceptance

- support for research data, including large and complex data types

- gold Open Access which fosters wider collaboration and increased citations

- maximum visibility for your research: over $100 \mathrm{M}$ website views per year

At BMC, research is always in progress.

Learn more biomedcentral.com/submissions 